RASĀYAN J. Chem.

Vol. 13 | No. 1 |448 - 463| January - March | 2020 ISSN: 0974-1496 | e-ISSN: 0976-0083 | CODEN: RJCABP http://www.rasayanjournal.com http://www.rasayanjournal.co.in

\title{
COMPARATIVE STUDY ON ADSORPTION OF CATIONIQUE DYE ONTO EXPANDED PERLITE AND NATURAL CLAY
}

\author{
B. Damiyine*, A. Guenbour and R. Boussen \\ Laboratory of Materials Nanotechnology and Environment, Department of Chemistry, Faculty of \\ Science, University Mohammed V, Rabat, Morocco \\ *E-mail: brahimgp@gmail.com
}

\begin{abstract}
The main purpose of this study is to guide the effectiveness of Expanded Perlite (EP) and Natural Moroccan Clay (NMC) adsorbents in removing cationic textile dyes from solution.

To this end, the batch adsorption experiment explored the adsorption of Rhodamine B (RB) by EP and NMC, and therefore the adsorption was accompanied by UV-Vis spectrophotometry technique in an exceedingly specially sorption cell. The effect of temperature on the adsorption isotherm was also evaluated to examine the adsorption phenomenon. Adsorption kinetics was studied by using three different models i.e. pseudo-first-order, pseudosecond-order and intra-particle diffusion model. The findings of kinetic models reveal that the pseudo-second-order model describes well the adsorption process. The removal of dye by the two adsorbents is favorable in the basic medium. The thermodynamic results show that the adsorption process of RB on both adsorbents is spontaneous and endothermic. The results obtained in this work highlight that NMC is more effective than EP for removing of RB dye.

Keywords: Adsorption Isotherm, Natural Moroccan Clay, Expanded Perlite, Kinetics Studies, Rhodamine B.
\end{abstract}

(C) RASĀYAN. All rights reserved

\section{INTRODUCTION}

The use of organic dyes in aqueous solution could have negative effects on humans and aquatic life due to their toxicity. In addition, the discharge of effluents containing organic dyes into receiving waters prevents the diffusion of light in the aqueous phase. ${ }^{1-2}$ Indeed, the presence of traces of these micropollutants $(<1 \mathrm{ppm})$ in industrial wastewater is highly visible and undesirable. Therefore, in order to remove dyes from industrial effluents, different chemical, physical and biological processes have been already used. Some of these conventional waste treatment technologies are run-off filtration, chemical coagulation of activated sludge, flocculation, oxidation or ozonation, membrane separation, photodegradation and adsorption.

In this present work, two types of natural adsorbents were selected for Rhodamine B adsorption i.e. Expanded Perlite (EP) and natural MoroccanClay (NMC).-The objective of this work is to examine and understand the kinetics of adsorption, to describe the adsorption rate and mechanism, determine the factors controlling the adsorption rate and calculate the system's activation energy. The impact on RB adsorption speed, $\mathrm{pH}$ of the solution, initial concentration, contact time and temperature of the solution was assessed.

\section{Natural Moroccan Clay}

\section{EXPERIMENTAL}

The NMC sample was collected from a quarry located in the region of "Shoul" (Morocco). ${ }^{3,4}$ The sample was then sieved and dried for $1 \mathrm{~h}$ at $110^{\circ} \mathrm{C}$. The sample was vigorously stirred for $12 \mathrm{~h}$ in $20 \mathrm{ml}$ of absolute ethanol, washed with distilled water, harvested through vacuum filtration, and dried for $4 \mathrm{~h}$ in a static air oven at $90{ }^{\circ} \mathrm{C}$.

\section{Expanded Perlite}

The EP sample was obtained from Tasper Perlite, Aksemsettin Mah. Fatih Bulvari No: 590 Sultanbeyli 34925 Istanbul Turkey. The sample of the EP was sewn by a 90-mesh sieve and dried for $1 \mathrm{~h}$ at $110^{\circ} \mathrm{C} .{ }^{6}$

Rasayan J. Chem., 13(1), 448-463(2020)

http://dx.doi.org/10.31788/RJC.2020.1315588 
RASĀYAN J. Chem.

Vol. 13 | No. 1 |448 - 463| January - March | 2020

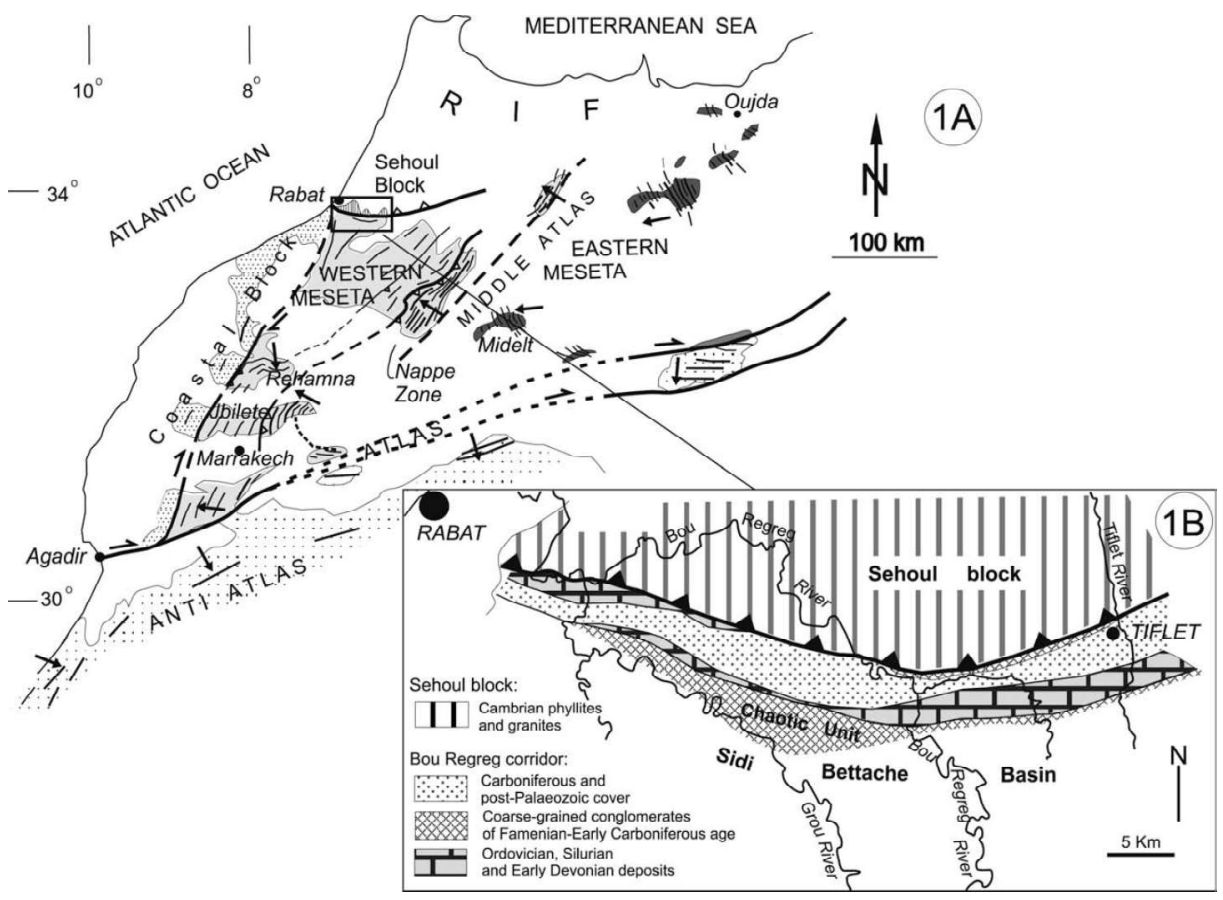

Fig.-1: Geological Map of the Investigated Area. ${ }^{5}$

\section{Characterization of the Adsorbents}

The chemical composition of adsorbents is investigated using X-Ray diffraction (XDR) (Siemens d5000), Fourier-transform infrared spectroscopy (BRUKER Tensor 27 FTIR) and energy dispersive X-ray (EDX) (HORIBA XGT-1000).

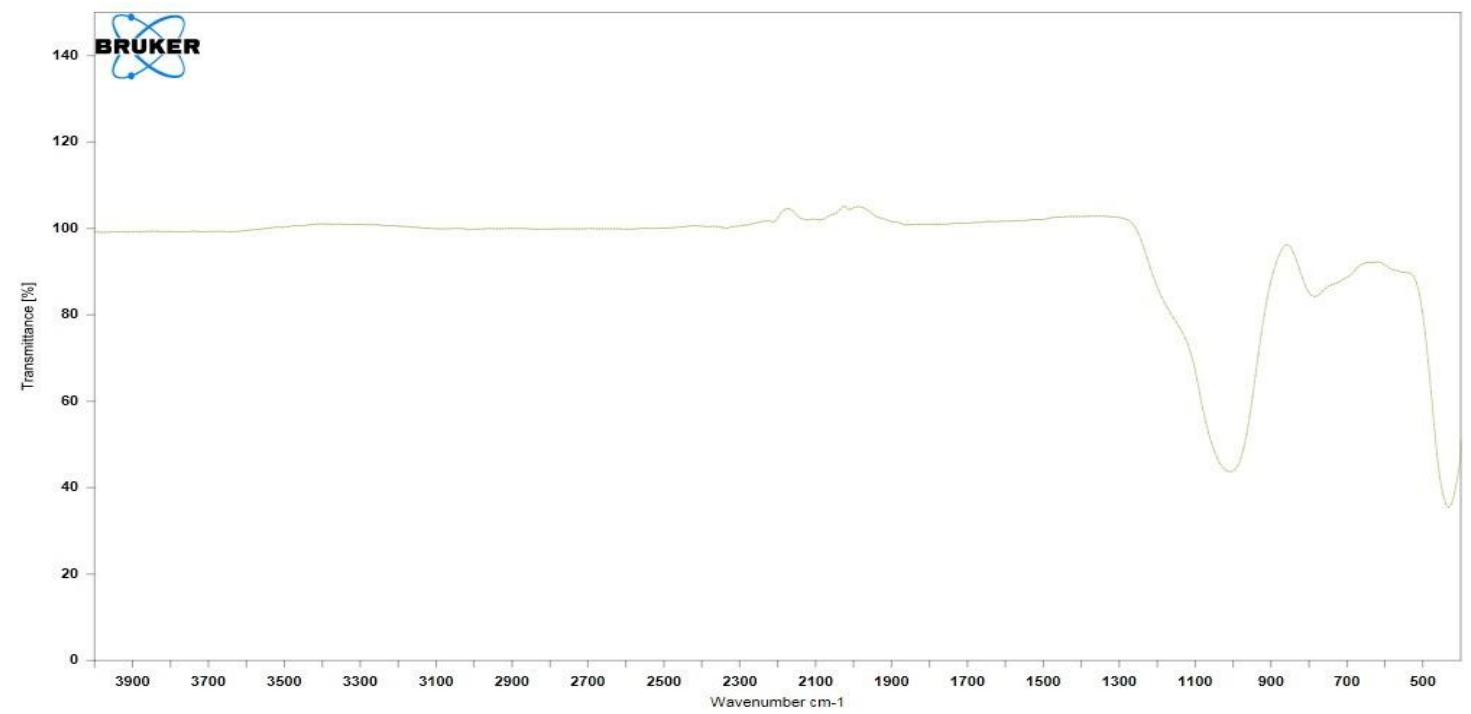

Fig.-2: FT-IR Spectrum of Expanded Perlite

The wavelength of $1000 \mathrm{~cm}^{-1}$ and $470 \mathrm{~cm}^{-1}$ wavelength IR bands are band features of silicon which is Perlite main component.

From (Fig.-3), the $1399.95 \mathrm{~cm}^{-1}$ wavelength bands, $870.03 \mathrm{~cm}^{-1}$ and $708.85 \mathrm{~cm}^{-1}$ are bands characteristic of calcium carbonate, the $1009.13 \mathrm{~cm}^{-1}$ wavelength band is a silicon distinctive band. ${ }^{7}$ NMC XRD analysis confirms the presence of silicon oxide and molecules of calcium carbonate. 
RASĀYAN J. Chem.

Vol. 13 | No. 1 |448 - 463| January - March | 2020

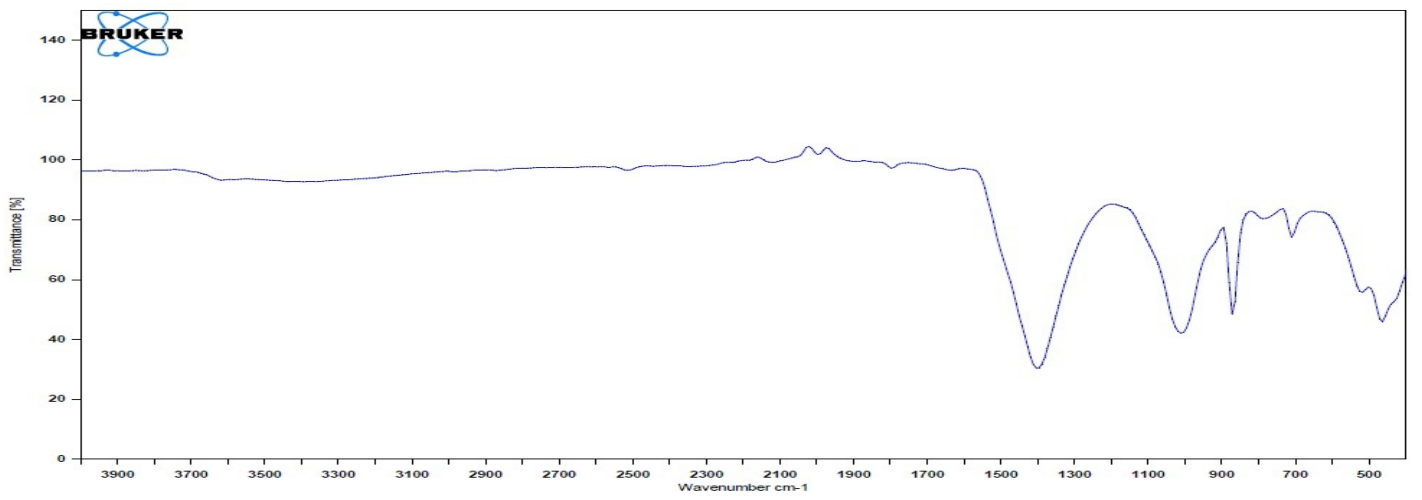

Fig.-3: FT-IR Spectrum of NMC
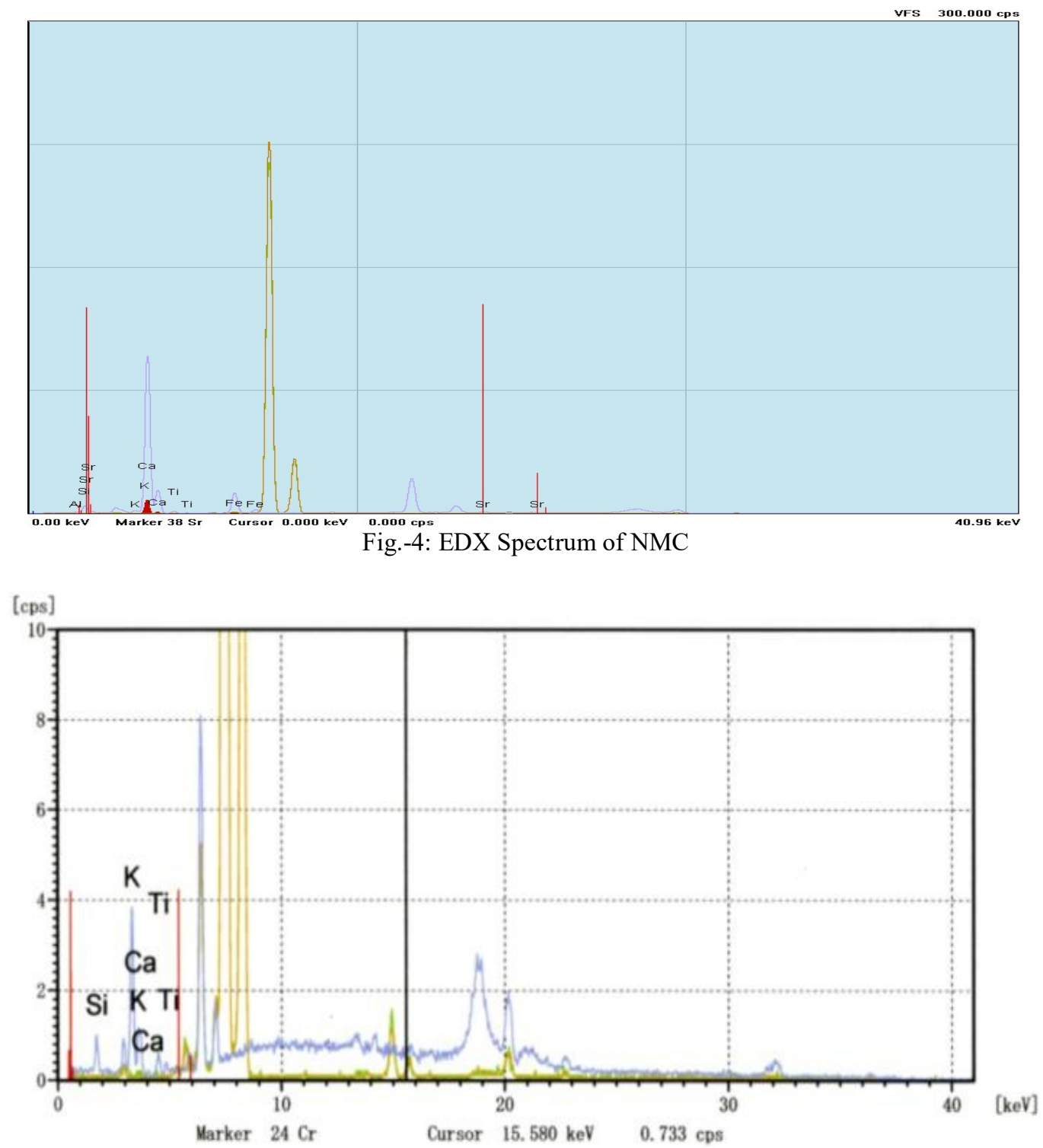

Fig.-5: EDX Spectrum of Expanded Perlite. 
RASĀYAN J. Chem.

Vol. 13 | No. 1 |448 - 463| January - March | 2020

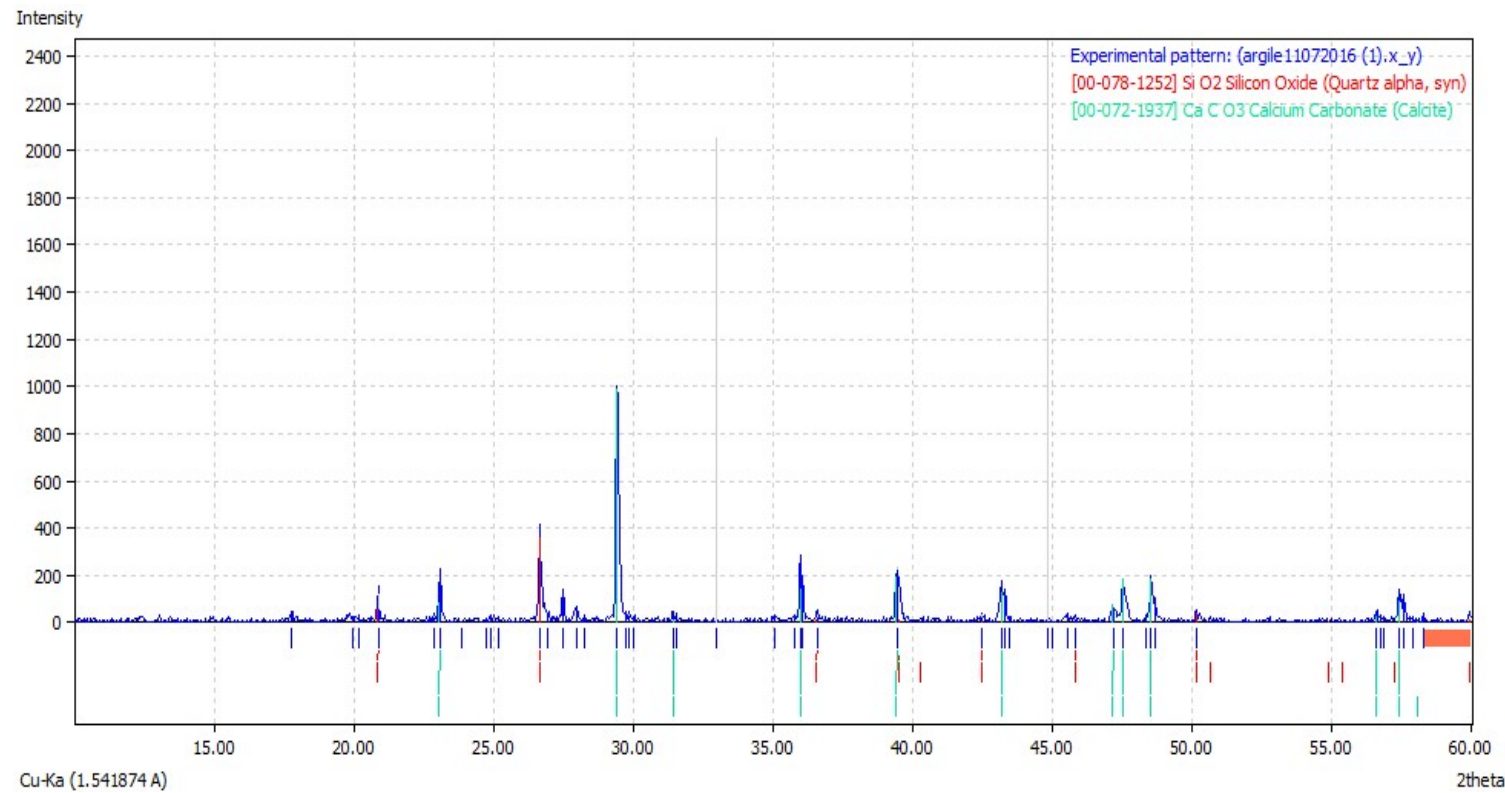

Fig.-6: XRD Spectrum of NMC.

Table-1: Chemical Composition of NMC.

\begin{tabular}{c|c}
\hline Major Elements & Composition (Wt \%) \\
\hline $\mathrm{Ca}$ & 77.97 \\
\hline $\mathrm{Si}$ & 11.46 \\
\hline $\mathrm{Fe}$ & 7.74 \\
\hline $\mathrm{Al}$ & 1.98 \\
\hline $\mathrm{K}$ & 0.85
\end{tabular}

\section{Rhodamine B}

The cationic dye used as an adsorbate in the present work, Rhodamine B (RB). It was provided by Merck Millipore Corporation, Germany). The chemical structure of the dye is given in (Fig.-7).<smiles></smiles>

Fig.-7: Rhodamine B

Studies of batch mode adsorption were conducted to study the impact of different parameters such as initial concentration, contact time, solution temperature and $\mathrm{pH}$ of the solution to remove $\mathrm{RB}$ dye.

Batch adsorption studies were conducted by adding $0.01 \mathrm{~g}$ of adsorbent to Erlenmeyer $250 \mathrm{~mL}$ flasks containing $50 \mathrm{~mL}$ of various original $\mathrm{RB}$ solution levels, the flasks were moved by a magnetic stirrer at $500 \mathrm{rpm}$.

The adsorbent was isolated and centrifuged for $15 \mathrm{~min}$ at $3000 \mathrm{rpm}$, the concentration of $\mathrm{RB}$ in centrifugation was determined by a visible spectrophotometer (Jasco V-670 spectrophotometer) at a $\lambda$ $\max$ is $554 \mathrm{~nm}$. The quantity of adsorbed dye at qe equilibrium $(\mathrm{mg} / \mathrm{g})$ and the proportion of removal were calculated using the following equations: 
RASĀYAN J. Chem.

Vol. 13 | No. 1 |448 - 463| January - March | 2020

$\mathrm{qe}=\left(\mathrm{C}_{0}-\mathrm{C}_{\mathrm{e}}\right) \mathrm{V} / \mathrm{W}$

$\%$ removal $=\left(\left(\mathrm{C}_{0}-\mathrm{C}_{\mathrm{e}}\right) / \mathrm{C}_{0}\right) \times 100$

$\mathrm{C}_{0}$ and $\mathrm{Ce}$ : initial and equilibrium concentrations of dye respectively $(\mathrm{mg} / \mathrm{L})$.

$\mathrm{V}$ : volume of dye solution (L).

$\mathrm{W}$ : the weight of adsorbent used (g).

\section{Effect of Contact Time}

RESULTS AND DISCUSSION

(Fig.-8 and 9) show the proportion of RB adsorption as a function of the contact time. As can be observed in this figures, the adsorption of RB improved by contact time and achieved a high peak value of $79.13 \%$ for NMC and $29.00 \%$ for EP with a concentration initial of $20 \mathrm{mg} / \mathrm{L}$. Increasing the contact time lead to more sensitive modifications in the percentage of adsorption. Consequently, RB adsorption peaked at 30 and $270 \mathrm{~min}$, respectively. These values were selected as the optimum time of contact.

\section{Effect of pH}

The dye solution's $\mathrm{pH}$ is one of the most significant parameters since the $\mathrm{pH}$ of the solution heavily affects the functional group protonation on the surface of the biosorbent and the chemistry of the dye molecules.

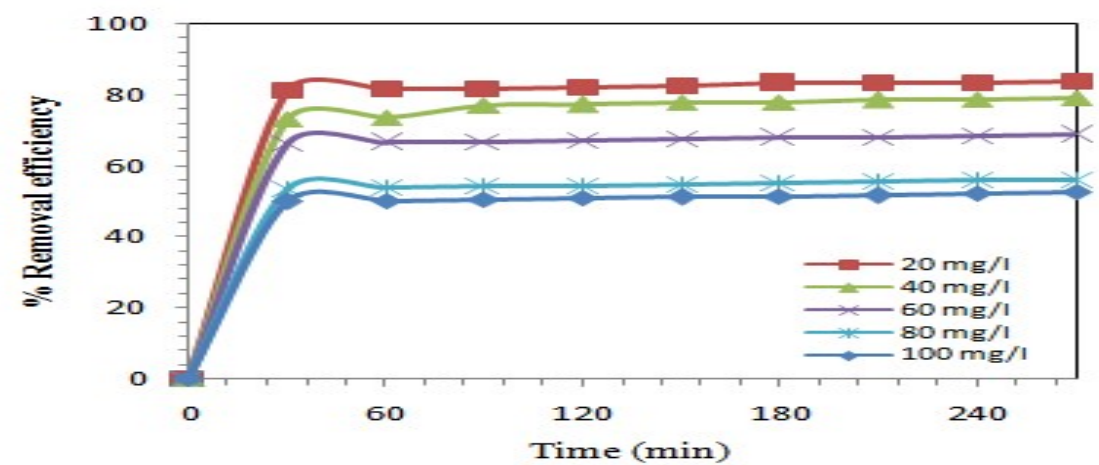

Fig.-8: Effect of Contact Time on Adsorption of RB onto NMC (Adsorbent Dose $=0.01 \mathrm{~g} / 50 \mathrm{~mL}, \mathrm{~T}=25^{\circ} \mathrm{C}$ )

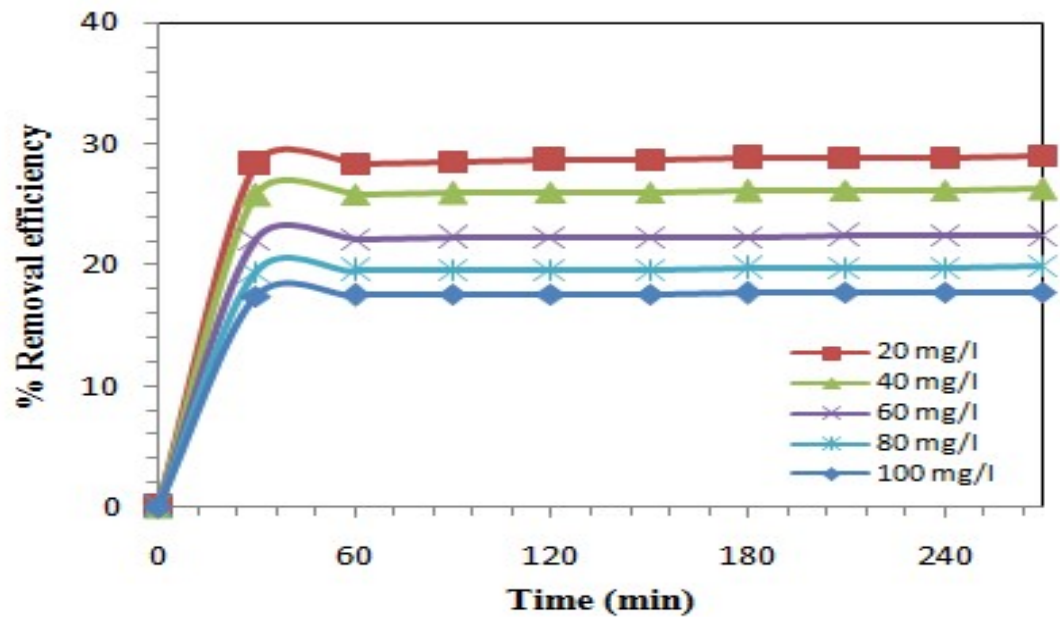

Fig.-9: Effect of Contact Time on Adsorption of RB onto EP(Adsorbent Dose $=0.01 \mathrm{~g} / 50 \mathrm{~mL}, \mathrm{~T}=25^{\circ} \mathrm{C}$ ) 
RASĀYAN J. Chem.

Vol. 13 | No. 1 |448 - 463| January - March | 2020

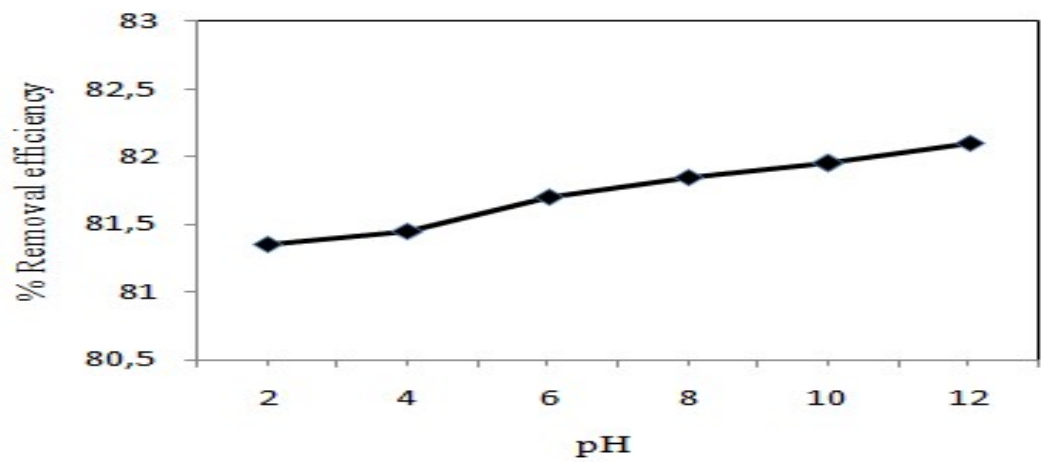

Fig.-10: Effect of $\mathrm{pH}$ on the Removal of RB onto NMC. (Adsorbent dose $=0.01 \mathrm{~g} / 50 \mathrm{~mL}, \mathrm{C}=20 \mathrm{mg} / \mathrm{L}, \mathrm{t}=60 \mathrm{~min}$, $\left.\mathrm{T}=25^{\circ} \mathrm{C}\right)$.

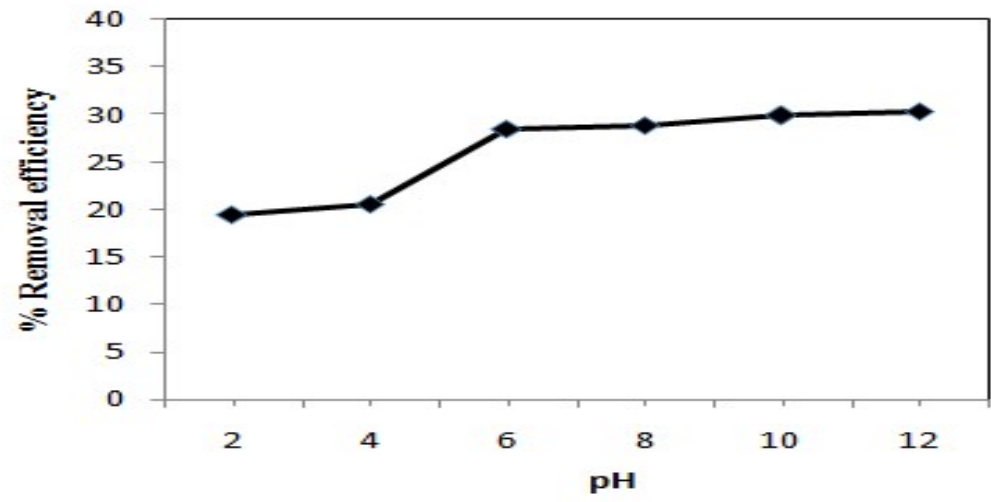

Fig.-11: Effect of $\mathrm{pH}$ on the Removal of RB onto EP. (Adsorbent dose $=0.01 \mathrm{~g} / 50 \mathrm{~mL}, \mathrm{C}=20 \mathrm{mg} / \mathrm{L}, \mathrm{t}=60 \mathrm{~min}$, $\left.\mathrm{T}=25^{\circ} \mathrm{C}\right)$.

As can be seen in (Fig.-10 and 11), the impact of initial pH on NMC and EP adsorption of RB was explored by varying the dye solution $\mathrm{pH}$ from 2 to 12 and $20 \mathrm{mg} / \mathrm{L}$ concentration. The figures show that the adsorbent adsorption capability decreased with $\mathrm{pH}$ values from $81.70 \%$ to $82.10 \%$ with NMC and from $19.45 \%$ to $30.40 \%$ with NMC and $\mathrm{EP}$, respectively.

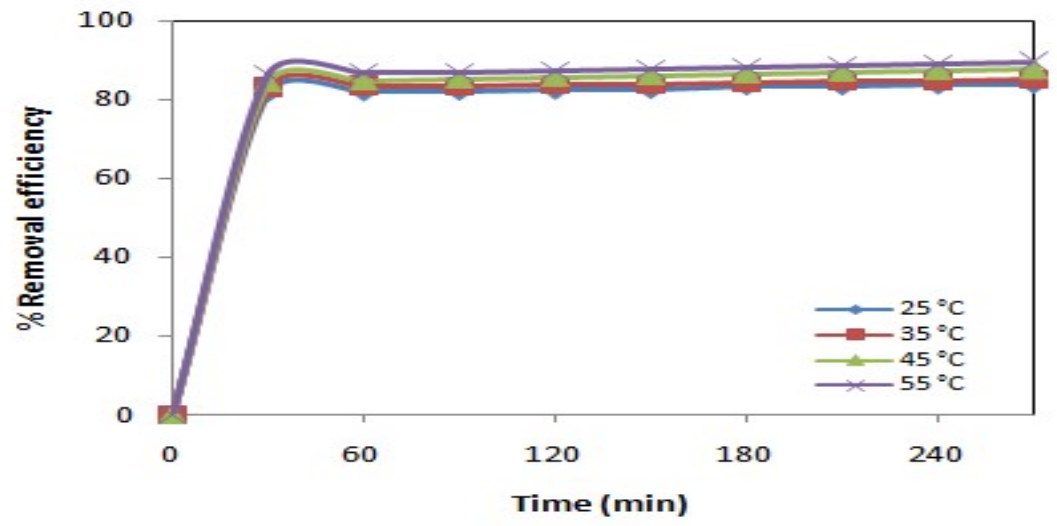

Fig.-12: Effect of Temperature on the Adsorption Kinetics of RB onto NMC (Adsorbent Dose $=0.01 \mathrm{~g} / 50 \mathrm{~mL}$,

\section{Effect of Temperature}

$\mathrm{pH}=7$ ).

Research of adsorption reaction temperature reliance provides useful data about the change in enthalpy during adsorption. The temperature effect on the adsorption rate was studied by conducting a series of experiments for $\mathrm{NMC}$ and $\mathrm{EP}$ at different temperatures i.e. $25,35,45$ and $55^{\circ} \mathrm{C}$. 
RASĀYAN J. Chem.

Vol. 13 | No. 1 |448 - 463| January - March | 2020

(Fig.-12 and 13) show that the adsorption of RB using NMC and EP indicates that the adsorption process is endothermic in nature when the temperature is from 25 to $55^{\circ} \mathrm{C}$, the $\mathrm{pH}=7$ and $\mathrm{C}_{0}=20 \mathrm{mg} / \mathrm{L}$.

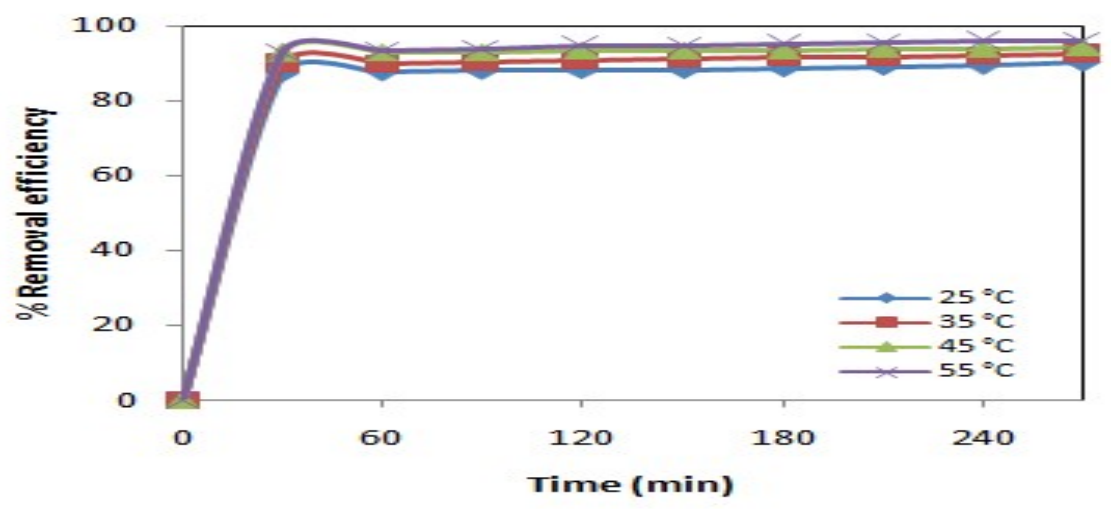

Fig.-13: Effect of Temperature on the Adsorption Kinetics of RB onto EP (Adsorbent dose $=0.01 \mathrm{~g} / 50 \mathrm{~mL}, \mathrm{pH}=7$ ).

The rise in the equilibrium adsorption of dye with temperature shows that the removal of dye by adsorption on NMC and EP favors a high temperature. ${ }^{8}$ This may result from increased mobility with the temperature of the big dye ion. a growing amount of molecules can also gain enough energy to interact with active surface locations. In addition, rising temperature could generate a swelling impact within the clay's inner framework allowing for further penetration of big dyes. ${ }^{9}$

\section{Effect of the Initial Concentration of Dye}

The effect in adsorption ability as the original concentration of RB dye increases due to a rise in the number of RB dye molecules accessible to adsorbent binding sites. The active sites become saturated at higher concentrations of RB dye and the capacity of adsorption approaches a constant value.

\section{Adsorption Isotherm}

The adsorption isotherms depict the amount adsorbed to equilibrium at a specified temperature depending on the concentration of the aqueous solution.

Firstly, the adsorption isotherm models are usually used to portray the relationships between the adsorbent and the adsorbent when the adsorption method reaches equilibrium.

Secondly, they allow the extraction from adsorption of the significant parameters for system design. The three isotherm models, Freundlich, Langmuir and Temkin, evaluated the adsorption information.

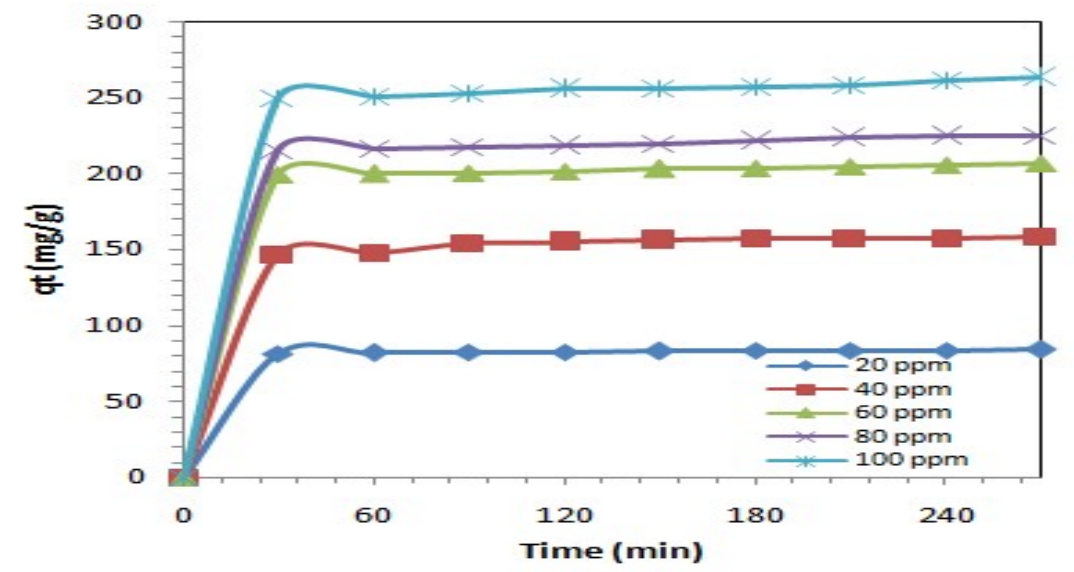

Fig.-14: Effect of Concentration on the Removal of RB onto MNC (Adsorbent Dose $=0.01 \mathrm{~g} / 50 \mathrm{~mL}, \mathrm{pH}=7$, $\mathrm{T}=25^{\circ} \mathrm{C}$ ).

454 
RASĀYAN J. Chem.

Vol. 13 | No. 1 |448 - 463| January - March | 2020

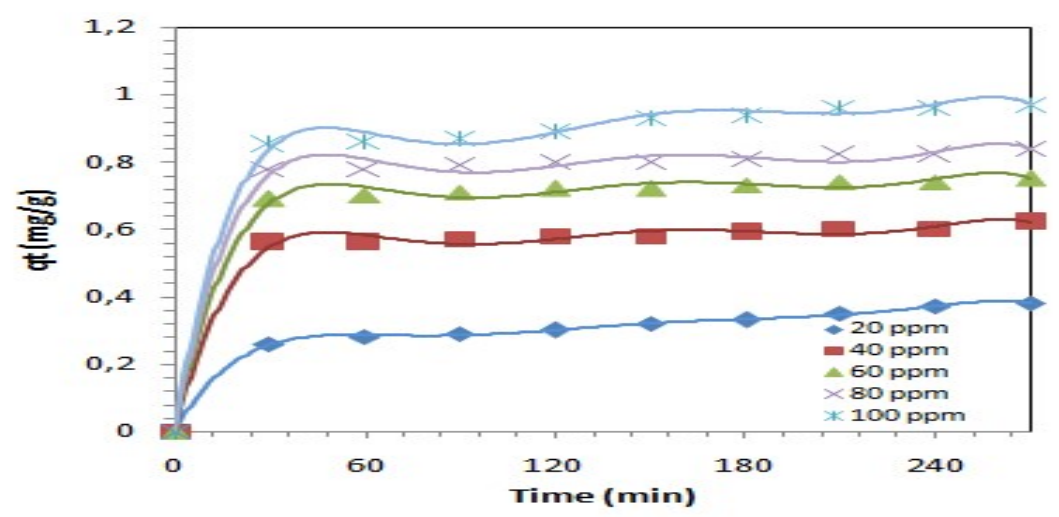

Fig.-15: Effect of Concentration on the Removal of RB onto $\mathrm{EP}\left(\right.$ Adsorbent Dose $\left.=0.01 \mathrm{~g} / 50 \mathrm{~mL}, \mathrm{pH}=7, \mathrm{~T}=25^{\circ} \mathrm{C}\right)$.

\section{Langmuir Adsorption Isotherm}

On a uniform surface with a finite number of adsorption sites, the Langmuir isotherm assumes monolayer adsorption. Once a site has been filled, there can be no additional adsorption at that site. As such the surface will eventually reach a saturation point where the maximum adsorption of the surface will be achieved. ${ }^{10}$

The linear form of the Langmuir isotherm model is described, ${ }^{11}$ as:

$$
\frac{\mathrm{C}_{\mathrm{e}}}{\mathrm{Q}_{\mathrm{e}}}=\frac{1}{\mathrm{~K}_{\mathrm{L}} \mathrm{Q}_{\mathrm{m}}}+\frac{1}{\mathrm{Q}_{\mathrm{m}}} \mathrm{C}_{\mathrm{e}}
$$

$\mathrm{C}_{\mathrm{e}}$ : equilibrium concentration in the solution $(\mathrm{mg} / \mathrm{L})$.

$\mathrm{Q}_{\mathrm{e}}$ : equilibrium uptake on the adsorbent $(\mathrm{mg} / \mathrm{g})$.

$\mathrm{Q}_{\mathrm{m}}$ : maximum adsorption capacity $(\mathrm{mg} / \mathrm{g})$.

$\mathrm{K}_{\mathrm{L}}$ : Langmuir constant that is related to the affinity of binding sites and is linked to the energy of adsorption (1/g).

The linear plot $C_{e} / Q_{e}$ versus $C_{e}$, which has a $1 / Q_{m}$ curve and $1 / K_{L} Q_{m}$ curve as shown in (Fig.-16 and 17), can determine these constants. From the values of the regression correlation coefficient $\left(\mathrm{R}^{2}\right)$ which are considered to be a measure of the fitness of experimental data on the model of the isotherm is shown in Table-2, it shows that the Langmuir equation represents very well RB adsorption process on NMC and EP at different temperatures, the $\mathrm{R}^{2}$ values for NMC and EP are 0.99 , indicating a good mathematical fit.

On the other hand, it can be anticipated from Table- 2 that an endothermic process is the RB adsorption on the NMC and EP. Where RB $\left(\mathrm{Q}_{\mathrm{m}}\right)$ monolayer adsorption capability improved as the temperature of the solution risen.

This important property of the Langmuir isotherm can be described in terms of a dimensionless factor, $\mathrm{R}_{\mathrm{L}}$, which is defined as follows:

$$
\mathrm{R}_{\mathrm{L}}=\frac{1}{1+\mathrm{K}_{\mathrm{L}} \mathrm{C}_{0}}
$$

$\mathrm{K}_{\mathrm{L}}$ : Langmuir constant.

$\mathrm{C}_{0}$ : initial $\mathrm{RB}$ concentration.

$\mathrm{R}_{\mathrm{L}}$ : indicate the type of isotherm to be irreversible $\left(\mathrm{R}_{\mathrm{L}}=0\right)$, favorable $\left(0<\mathrm{R}_{\mathrm{L}}<1\right)$, linear $\left(\mathrm{R}_{\mathrm{L}}=1\right)$ or unfavorable $\left(\mathrm{R}_{\mathrm{L}}>1\right){ }^{12}$

The $\mathrm{R}_{\mathrm{L}}$ values acquired for NMC in this study ranged from 0 to 1 as shown in Table-2. These values support the earlier observation where the isotherm of Langmuir was favorable for RB adsorption for all temperatures studied. For EP adsorption $\left(\mathrm{R}_{\mathrm{L}}=1\right)$, Langmuir isotherm has been linear for all temperatures studied. 
RASĀYAN J. Chem.

Vol. 13 | No. 1 |448 - 463| January - March | 2020

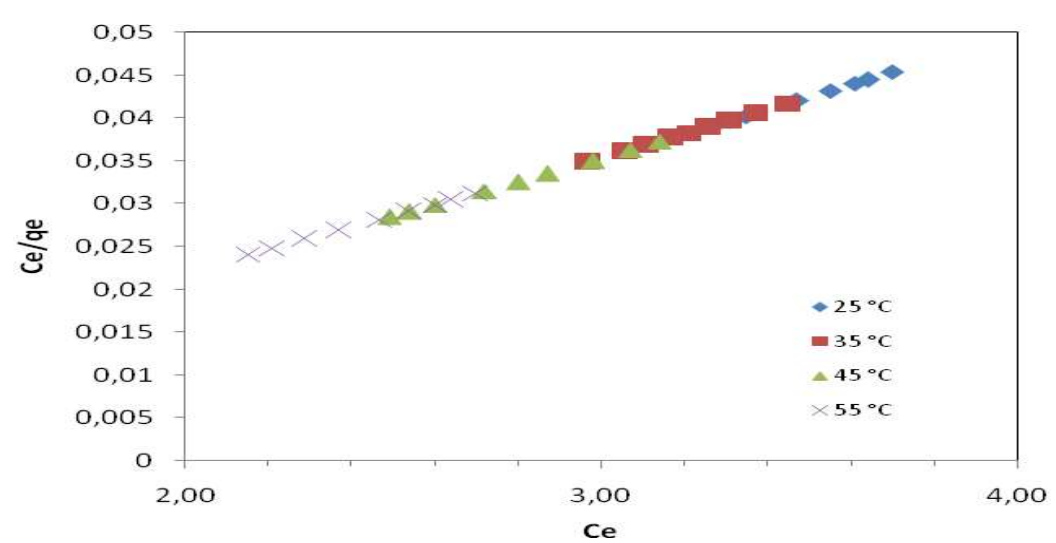

Fig.-16: Langmuir Isotherm for RB Adsorption onto MNC.

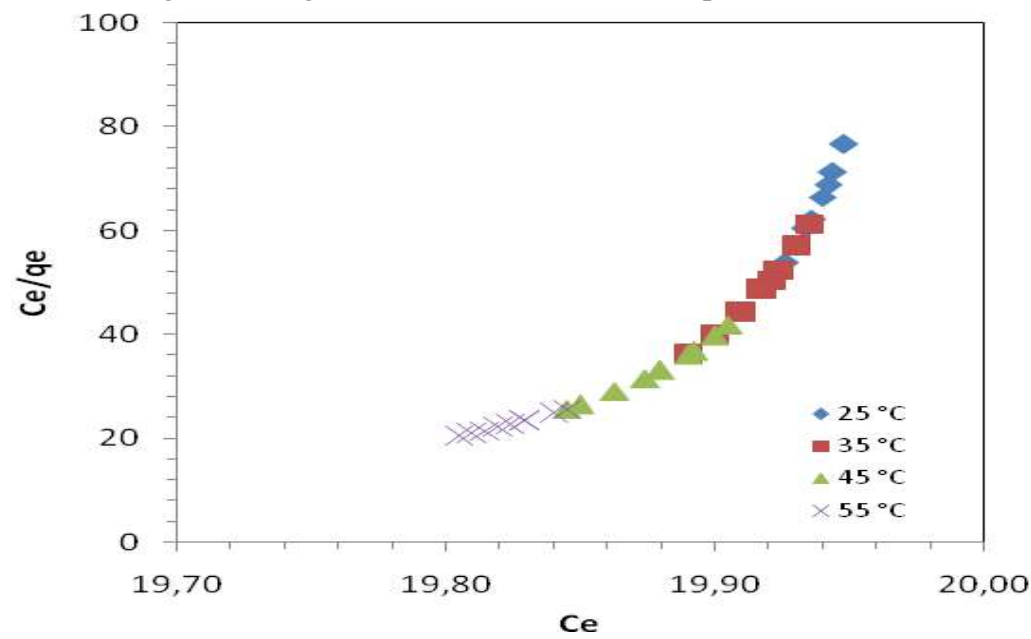

Fig.-17: Langmuir Isotherm for RB Adsorption onto EP.

\section{Freundlich Adsorption Isotherm}

By using the Freundlich equation, the acquired experimental RB uptake values were also evaluated. For multilayer adsorption, the Freundlich isotherm model is valid on a heterogeneous adsorbent surface with no uniform heat distribution of adsorption. It is possible to express Freundlich isotherm. ${ }^{13}$ by:

$$
\log Q_{e}=\log K_{F}+\frac{1}{n} \log C_{e}
$$

Where $\mathrm{n}$ and $\mathrm{K}_{\mathrm{F}}$ are Freundlich constants associated with adsorption intensity and adsorption capacity, respectively. From the $\log \mathrm{Q}_{\mathrm{e}}$ plot versus $\log \mathrm{C}_{\mathrm{e}}$, the Freundlich constants $\mathrm{K}_{\mathrm{F}}$ and $\mathrm{n}$ are achieved which should offer a straight line with a $1 / \mathrm{n}$ curve and $\log \mathrm{K}_{\mathrm{F}}$ intercept.

A linear relationship was noted between the parameters plotted at separate temperatures from (Fig.-18 and 19).

\section{Temkin Adsorption Isotherm}

The Temkin isotherm model assumes that owing to adsorbent - adsorbate interactions, the adsorption power reduces linearly with the surface area. Temkin isotherm. ${ }^{14}$ model's linear shape is described by:

$$
\mathrm{Q}_{\mathrm{e}}=\mathrm{B}_{\mathrm{t}} \ln _{\mathrm{t}}+\mathrm{B}_{\mathrm{t}} \ln \mathrm{C}_{\mathrm{e}}
$$

$\mathrm{B}_{\mathrm{t}}$ : Temkin constant related to heat of adsorption $(\mathrm{KJ} / \mathrm{mol})$.

$\mathrm{K}_{\mathrm{t}}$ : Temkin isotherm constant $(\mathrm{L} / \mathrm{g})$.

These constants were obtained from plotting $Q_{\mathrm{e}}$ versus $\operatorname{lnC}_{\mathrm{e}}$, are shown in (Fig.-20 and 21). Values of $\mathrm{B}_{\mathrm{t}}$ and $\mathrm{K}_{\mathrm{t}}$ are listed in Table-2. 
RASĀYAN J. Chem.

Vol. 13 | No. 1 |448 - 463| January - March | 2020

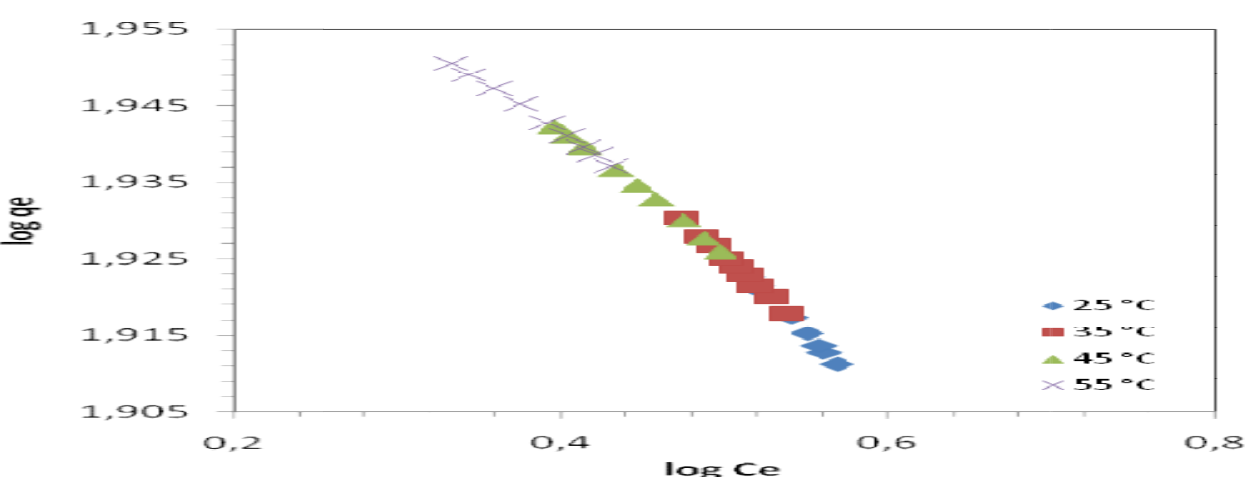

Fig.-18: Freundlich Isotherm for RB Adsorption onto NMC.

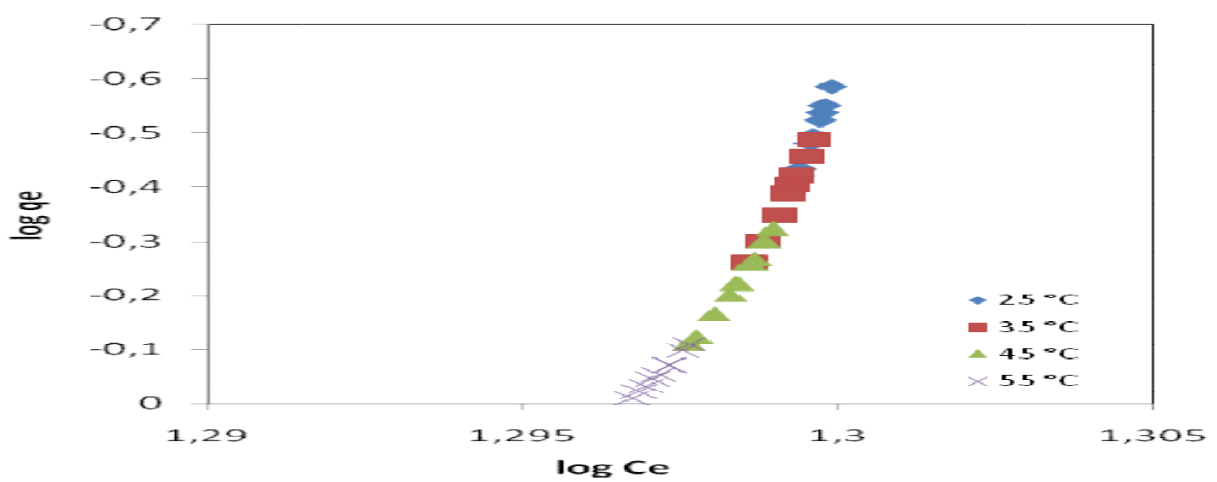

Fig.-19: Freundlich Isotherm for RB Adsorption onto EP.

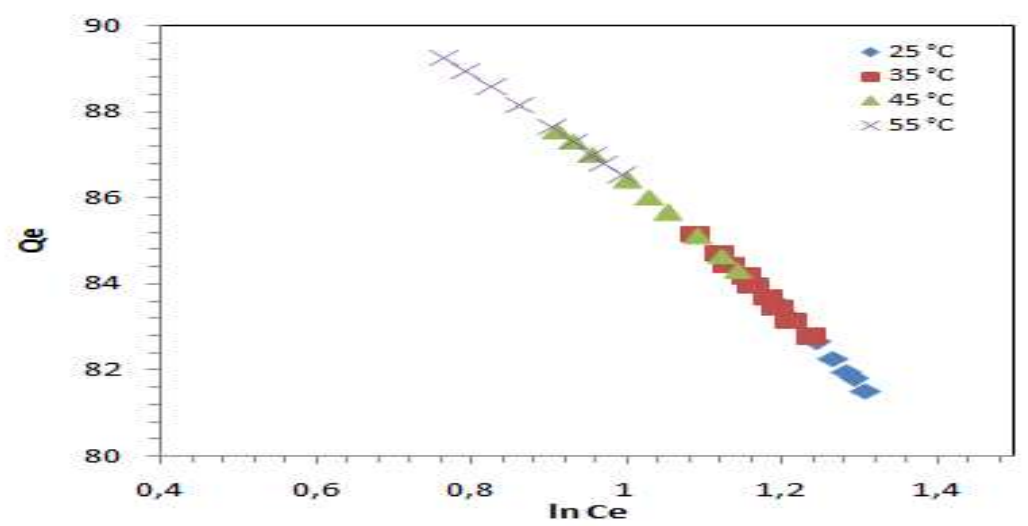

Fig.-20: Temkin Isotherm for RB Adsorption on to NMC.

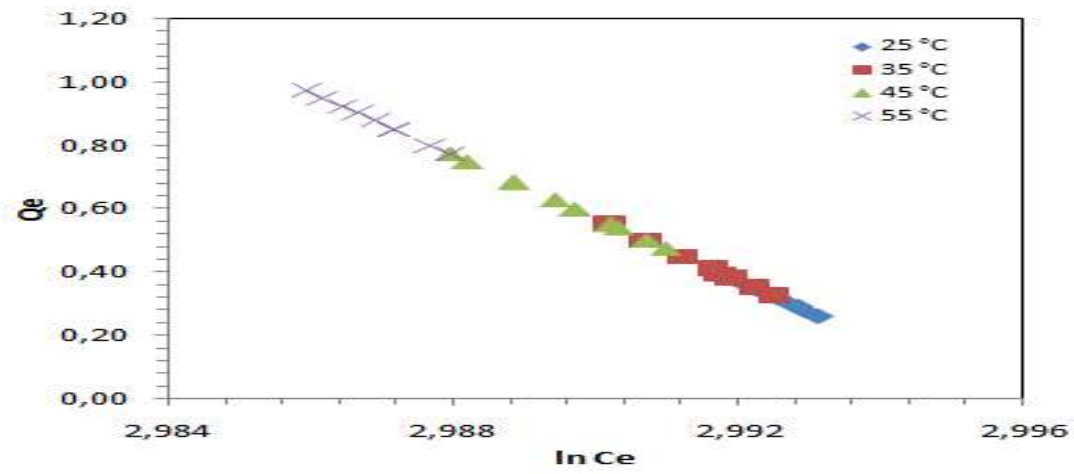

Fig.-21: Temkin Isotherm for RB Adsorption onto EP. 
RASĀYAN J. Chem.

Vol. 13 | No. 1 |448 - 463| January - March | 2020

Table-2: Adsorption Isotherm Constants for RB Adsorption on to NMC and EP

\begin{tabular}{|c|c|c|c|c|c|c|c|c|c|c|c|}
\hline \multirow[b]{2}{*}{ Adsorben } & \multirow[b]{2}{*}{$\begin{array}{c}\mathrm{T} \\
\left(\mathrm{C}^{\circ}\right)\end{array}$} & \multicolumn{4}{|c|}{ Langmuir Isotherm Constants } & \multicolumn{3}{|c|}{ Freundlich Isotherm Constants } & \multicolumn{3}{|c|}{$\begin{array}{c}\text { Temkin Isotherm } \\
\text { Constants }\end{array}$} \\
\hline & & $\begin{array}{c}\mathrm{q}_{\mathrm{m}} \\
(\mathrm{mg} / \mathrm{g})\end{array}$ & $\begin{array}{l}\mathrm{K}_{\mathrm{L}} \\
(\mathrm{L} / \mathrm{g})\end{array}$ & $\mathrm{R}^{2}$ & $\mathrm{R}_{\mathrm{L}}$ & $\begin{array}{c}\mathrm{K}_{\mathrm{F}} \\
(\mathrm{mg} / \mathrm{g} \\
\left.(\mathrm{L} / \mathrm{mg})^{1 / \mathrm{n}}\right)\end{array}$ & $\mathrm{n}$ & $\mathrm{R}^{2}$ & $\begin{array}{c}\mathrm{K}_{\mathrm{t}} \\
(\mathrm{L} / \mathrm{g})\end{array}$ & $\begin{array}{c}\mathrm{B}_{\mathrm{t}} \\
(\mathrm{KJ} / \mathrm{mol})\end{array}$ & $\mathrm{R}^{2}$ \\
\hline \multirow{4}{*}{ NMC } & 25 & 68.493 & .6782 & 9999 & 9664 & 107.103 & -4.796 & .9996 & 0.0024 & -17.249 & 0.99 \\
\hline & 35 & 70.422 & -1.9455 & 0.9999 & 0.9611 & 104.858 & -5.238 & 0.9992 & 0.0017 & -16.024 & 0.9995 \\
\hline & 45 & 74.074 & -2.5472 & 0.9999 & 0.9491 & 101.624 & -6.146 & 0.9986 & 0.0008 & -13.989 & 0.999 \\
\hline & 55 & 76.923 & -3.4211 & 0.9999 & 0.93 & & -1.2 & 0.999 & 0.0003 & -12.071 & 0.9991 \\
\hline \multirow{4}{*}{ EF } & 25 & $10^{-3}$ & 0.0508 & 0.98 & 1.0011 & $2.34 \times$ & $-3.20 \times 10^{-1}$ & 0.997 & 0.05 & -99.678 & 1.00 \\
\hline & 35 & $1.8 \times 10^{-03}$ & 0.0506 & 0.9735 & 1.0010 & $1.74 \times 10^{+301}$ & $-4.30 \times 10^{-03}$ & 0.9933 & 0.05 & -99.564 & 1.00 \\
\hline & 45 & $3.7 \times 10^{-03}$ & 0.0515 & 0.9816 & 1.0010 & $1.90 \times 10^{+208}$ & $-6.22 \times 10^{-03}$ & 0.9955 & 0.05 & -99.214 & 1.00 \\
\hline & 55 & $7.5 \times 10^{-03}$ & 0.0514 & 0.9952 & 1.0010 & $2.57 \times 10^{+147}$ & $-8.70 \times 10^{-03}$ & 0.9988 & 0.05 & -99.125 & 1.00 \\
\hline
\end{tabular}

\section{Adsorption Kinetics}

To examine the mechanism of the adsorption method, three streamlined kinetic models were introduced. First, the adsorption kinetics was evaluated by Lagergren's pseudo-first-order. ${ }^{15}$ equation as follows:

$$
\log \left(\mathrm{q}_{\mathrm{e}}-\mathrm{q}_{\mathrm{t}}\right)=\log \mathrm{q}_{\mathrm{e}}-\left(\frac{\mathrm{K}_{1}}{2,303}\right) \mathrm{t}
$$

Where qe and qt are the equilibrium amounts of RB adsorbed ( $\mathrm{mg} / \mathrm{g}$ ) and time $\mathrm{t}(\mathrm{h})$, respectively, and $\mathrm{k}_{1}$ $\left(\mathrm{g} \mathrm{mg}^{-1} \mathrm{~h}^{-1}\right)$ is the constant adsorption rate.

It is obvious from (Fig.-22 and 23) that for distinct original RB levels the values of $\mathrm{k}_{1}$ at $25{ }^{\circ} \mathrm{C}$ were calculated from the $\ln (\mathrm{qe}-\mathrm{qt})$ plots versus $\mathrm{t}$.

The $\mathrm{R}^{2}$ values obtained were relatively small and as shown in Table-3, the experimental qe values did not agree with the calculated values obtained from the linear plots.

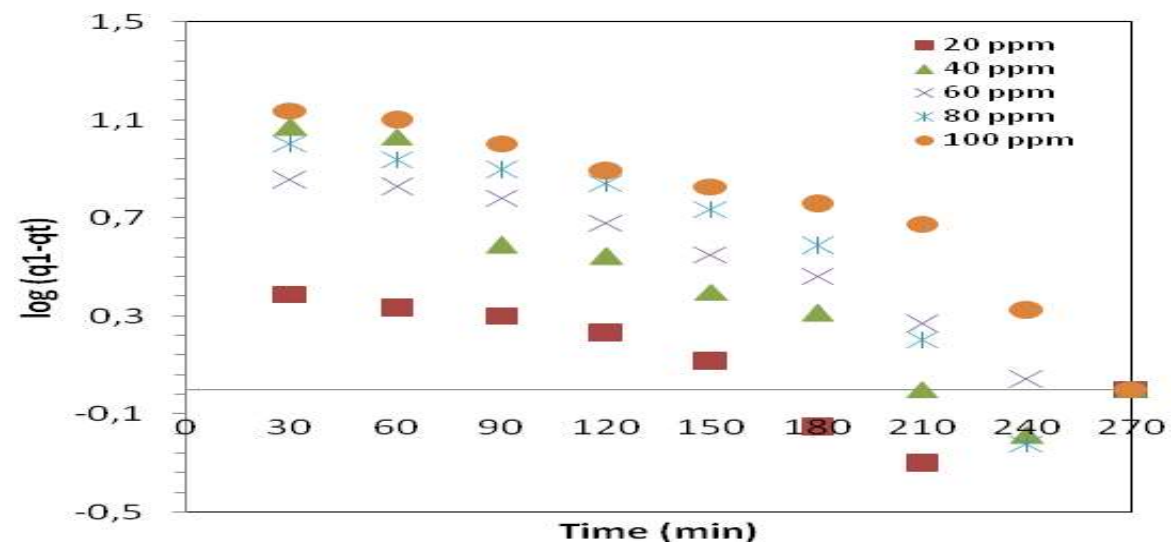

Fig.-22: Pseudo-First Order Kinetic Model for RB Adsorption onto NMC at Different Initial Concentrations.

On the other hand, the pseudo-second-order equation. ${ }^{16}$ based on equilibrium adsorption is expressed as:

$$
\frac{1}{\mathrm{q}_{\mathrm{t}}}=\frac{1}{\mathrm{~K}_{2} \mathrm{q}_{\mathrm{e}}^{2}}+\left(\frac{1}{\mathrm{q}_{\mathrm{e}}}\right) \mathrm{t}
$$

$\mathrm{K}_{2}\left(\mathrm{~g} \mathrm{mg}^{-1} \mathrm{~h}^{-1}\right)$ is the second-order adsorption constant. As shown in (Fig.-24 and 25), the linear plot of $\mathrm{t} / \mathrm{qt}$ versus $\mathrm{t}$ at $25^{\circ} \mathrm{C}$ yielded $\mathrm{R}^{2}$ values varying from 0.9997 to 1 for all NMC adsorbed RB levels and varying from 0.98 to 0.99 for all $\mathrm{EP}$ adsorbed RB levels. 
RASĀYAN J. Chem.

Vol. 13 | No. 1 |448 - 463| January - March | 2020

A strong agreement between the experimental and calculated qe values was also shown in Table-3, showing the applicability of this model to describe RB's adsorption method on NMC and EP.

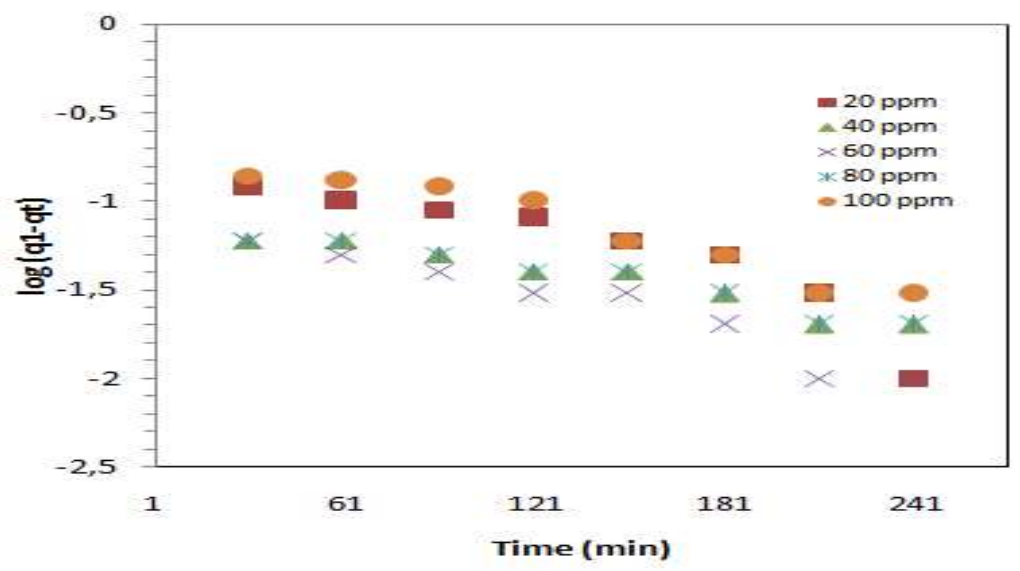

Fig.-23: Pseudo-First Order Kinetic Model for RB Adsorption onto EP at Different Initial Concentrations.

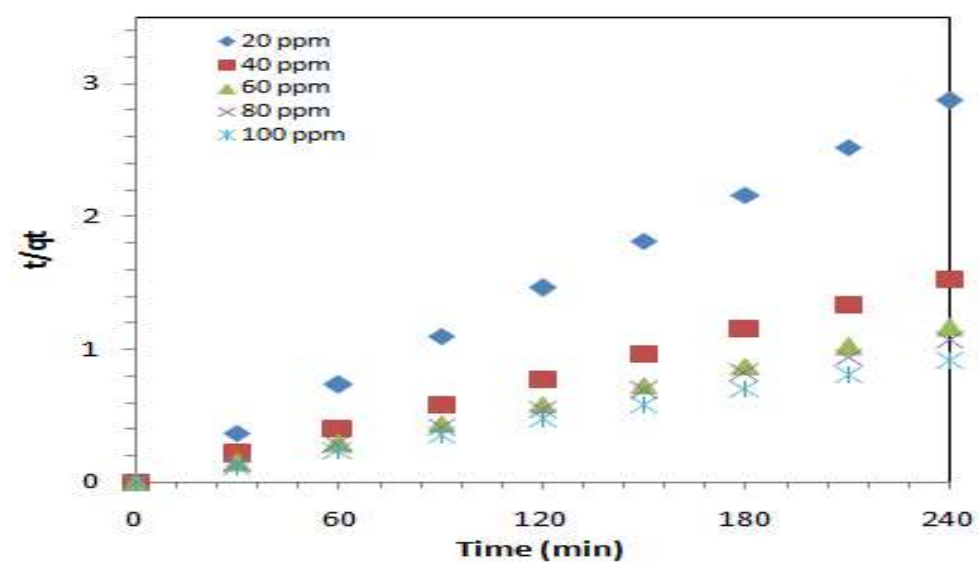

Fig.-24: Pseudo-Second Order Kinetic Model for RB Adsorption onto NMC at Different Initial Concentrations.

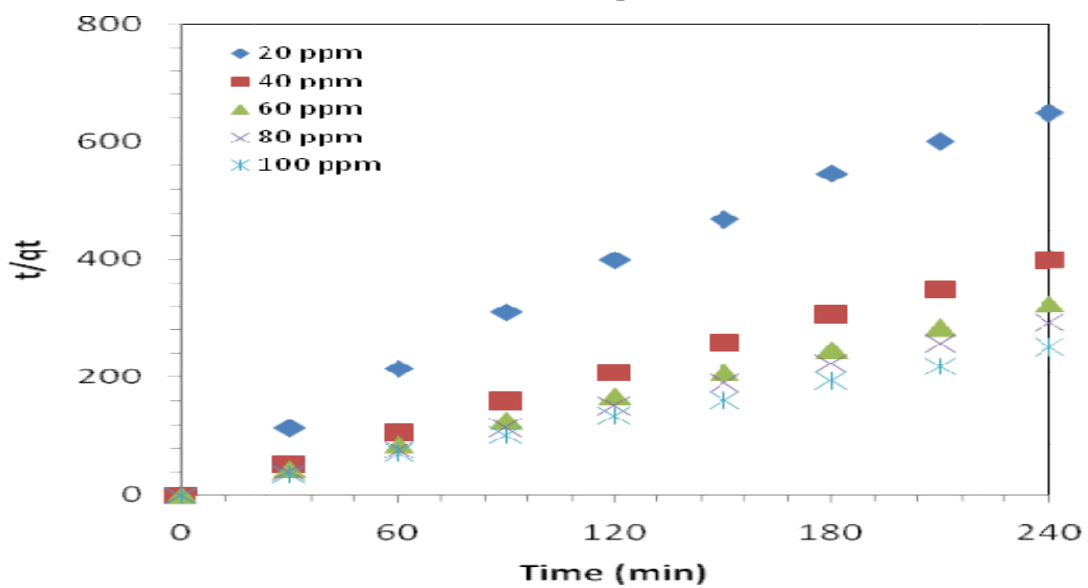

Fig.-25: Pseudo-Second Order Kinetic Model for RB Adsorption onto EP at Different Initial Concentrations

Intra-particle diffusion model. ${ }^{17}$ was screened to define the diffusion mechanism on the basis of the theory suggested by Weber and Morris. In line with this theory: 
RASĀYAN J. Chem.

Vol. 13 | No. 1 |448 - 463| January - March | 2020

$$
\mathrm{q}_{\mathrm{t}}=\mathrm{K}_{\mathrm{p}} \mathrm{t}^{1 / 2}+\mathrm{C}
$$

$\mathrm{C}$ is the intercept and $\mathrm{K}_{\mathrm{p}}$ is the intra-particule diffusion rate constant $\left(\mathrm{mol} \mathrm{min}^{-1 / 2} \mathrm{~g}^{-1}\right.$ ), is obtained from the slope of the straight line of qt versus $t^{1 / 2}$.

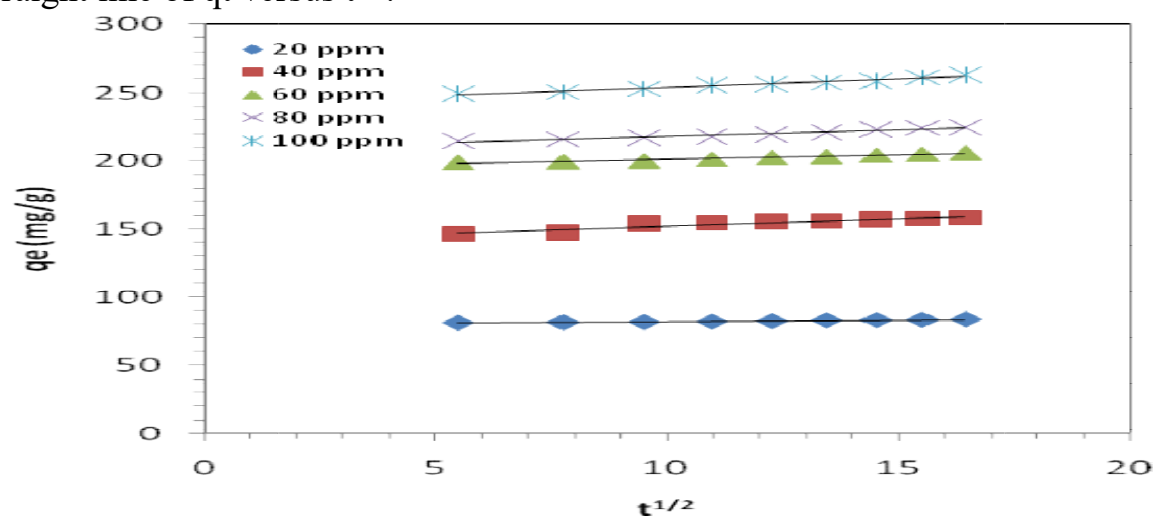

Fig.-26: Intra-particle Diffusion Kinetic Model for RB Adsorption onto NMC at Different Initial Concentrations.

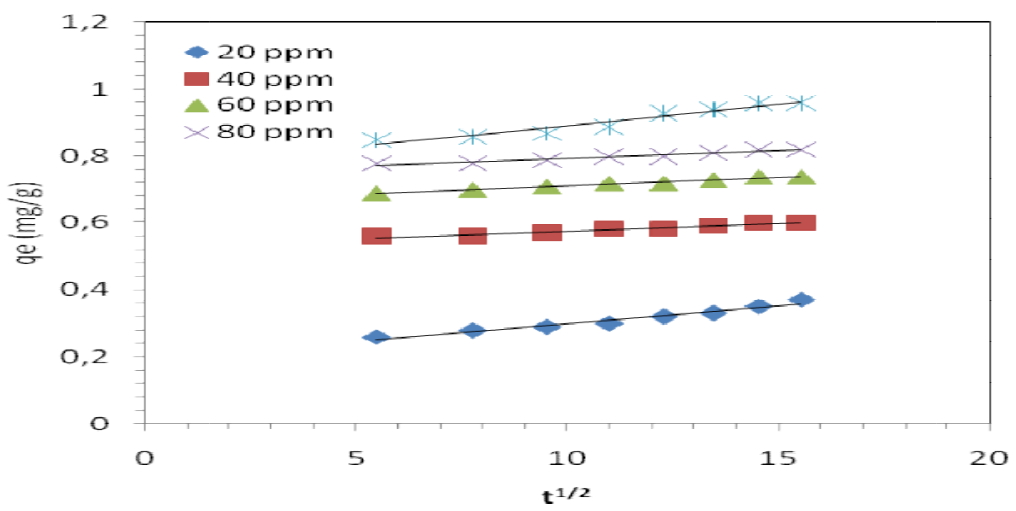

Fig.-27: Intra-particle Diffusion Kinetic Model for RB Adsorption onto EP at Different Initial Concentrations.

Table-3: Kinetic Parameters for the Adsorption of RB onto NMC and EP

\begin{tabular}{c|c|c|c|c|c|c|c|c|c|c|c}
\hline \multirow{2}{*}{ Clay } & \multirow{2}{*}{$\begin{array}{c}\mathrm{C}_{0} \\
(\mathrm{mg} / \mathrm{L})\end{array}$} & $\begin{array}{c}\mathrm{q}_{\mathrm{e}} \\
(\mathrm{mg} / \mathrm{g})\end{array}$ & \multicolumn{2}{|c|}{ Pseudo-first-order } & \multicolumn{2}{c|}{ Pseudo-second-order } & \multicolumn{3}{|c}{ Intra-particle diffusion } \\
\cline { 5 - 12 } & & $\mathrm{q}_{\mathrm{e}}$ & $\mathrm{K}_{1}$ & $\mathrm{R}^{2}$ & $\mathrm{q}_{\mathrm{e}}$ & $\mathrm{K}_{2}$ & $\mathrm{R}^{2}$ & $\mathrm{C}$ & $\mathrm{K}_{\mathrm{i}}$ & $\mathrm{R}^{2}$ \\
\hline \multirow{5}{*}{$\mathrm{NMC}$} & 20 & 83.95 & 4.36 & 0.0101 & 0.6884 & 84.034 & 0.0055 & 0.9999 & 79.928 & 0.237 & 0.956 \\
& 40 & 158.25 & 18.63 & 0.0136 & 0.9254 & 161.29 & 0.0016 & 0.9998 & 141.30 & 1.101 & 0.877 \\
& 60 & 206.45 & 11.77 & 0.0088 & 0.9522 & 208.33 & 0.0000 & 1.00 & 194.650 & 0.682 & 0.960 \\
& 80 & 225.00 & 21.64 & 0.0122 & 0.8614 & 227.27 & 0.0014 & 0.9997 & 208.45 & 0.982 & 0.952 \\
& 100 & 263.15 & 20.045 & 0.0078 & 0.8808 & 263.15 & 0.0014 & 0.9997 & 241.70 & 1.225 & 0.969 \\
\hline \multirow{5}{*}{ EP } & 20 & 0.38 & 0.2132 & -0.0101 & 0.8322 & 0.3696 & 0.1727 & 0.9843 & 0.1952 & 0.011 & 0.958 \\
& 40 & 0.62 & 0.0812 & -0.0058 & 0.9402 & 0.6028 & 0.5195 & 0.9993 & 0.5296 & 0.005 & 0.939 \\
& 60 & 0.75 & 0.0879 & -0.0090 & 0.9417 & 0.7433 & 0.4976 & 0.9996 & 0.6607 & 0.005 & 0.981 \\
& 80 & 0.84 & 0.0879 & -0.0058 & 0.9402 & 0.8227 & 0.5293 & 0.9996 & 0.7496 & 0.005 & 0.939 \\
& 100 & 0.97 & 0.2192 & -0.0085 & 0.9419 & 0.9721 & 1.0287 & 0.9980 & 0.7654 & 0.013 & 0.936 \\
\hline
\end{tabular}

\section{Thermodynamic Studies}

The thermodynamic parameters were determined from the following elements: the free energy variation $\left(\Delta \mathrm{G}^{\circ}\right)$, the enthalpy variation $\left(\Delta \mathrm{H}^{\circ}\right)$ and the entropy variation $\left(\Delta \mathrm{S}^{\circ}\right)$. These elements are calculated basing on the following equations: 
RASĀYAN J. Chem.

Vol. 13 | No. 1 |448 - 463| January - March | 2020

$$
\begin{aligned}
& \Delta \mathrm{G}^{\circ}=-\mathrm{RT} \ln \mathrm{K} \\
& \ln \mathrm{K}=\frac{\Delta \mathrm{S}^{\circ}}{\mathrm{R}}-\frac{\Delta \mathrm{H}^{\circ}}{\mathrm{RT}}
\end{aligned}
$$

Where,

$\mathrm{R}$ : the universal gas constant $\left(8.314 \mathrm{~J} \mathrm{~mol}^{-1} \mathrm{~K}^{-1}\right)$.

$\mathrm{T}$ : absolute temperature (Kelvin).

$\mathrm{K}$ : the equilibrium constant.

Equation (10) is known as the Van't Hoff equation, and it expresses a relationship between equilibrium constant and temperature. Plots of $\operatorname{lnK}_{\mathrm{b}}$ versus $1 / \mathrm{T}(1 / \mathrm{K})$ should be a straight line as shown in (Fig.-28 and 29).

The values of $\Delta \mathrm{H}^{\circ}$ and $\Delta \mathrm{S}^{\circ}$ for both NMC and EP adsorbents were calculated from the slope and intercept of Van't Hoff plote, respectively. ${ }^{18}$ The thermodynamic parameters associated with the adsorption of RB onto NMC and EP are listed in Table-4. The positive values of $\Delta \mathrm{G}^{\circ}$ for NMC adsorbent suggest that adsorption reaction requires energy to carry out. ${ }^{19}$

The negative values of $\Delta \mathrm{G}^{\circ}$ for $\mathrm{EP}$ adsorbent make the overall process spontaneous. ${ }^{20}$ The positive values of $\Delta \mathrm{H}^{\circ}$ indicate the endothermic nature of the adsorption process. The $\Delta \mathrm{S}^{\circ}$ values were found to be positive which suggests an increase in the randomness at the solid/solution interface during the adsorption. ${ }^{21,22}$ This further confirmed the endothermic nature of the adsorption process.

Table-4: Values of Thermodynamics Parameters for RB Adsorption onto NMC and EP

\begin{tabular}{c|c|c|c|c|c}
\hline \multirow{2}{*}{ Clay } & Temperature $(\mathrm{K})$ & $\begin{array}{c}\Delta \mathrm{G} \\
\left(\mathrm{KJ} \mathrm{mol}^{-1}\right)\end{array}$ & $\begin{array}{c}\Delta \mathrm{H} \\
\left(\mathrm{KJ} \mathrm{mol}^{-1}\right)\end{array}$ & $\begin{array}{c}\Delta \mathrm{S}^{-1}{ }^{-1} \\
\left(\mathrm{~kJ} \mathrm{~mol}^{-1}\right)\end{array}$ & $\mathrm{R}^{2}$ \\
\hline \multirow{5}{*}{ NMC } & 298.15 & 8.016 & 12.887 & 0.0701 & 0.9738 \\
\cline { 2 - 6 } & 308.15 & 8.717 & & & \\
\cline { 2 - 6 } & 318.15 & 9.418 & & & 0.9945 \\
\hline \multirow{5yyyyy}{*}{ EP } & 328.15 & 10.119 & & & \\
\cline { 2 - 6 } & 298.15 & -9.766 & 25.990 & & \\
\cline { 2 - 6 } & 308.15 & -9.221 & & & \\
\hline
\end{tabular}

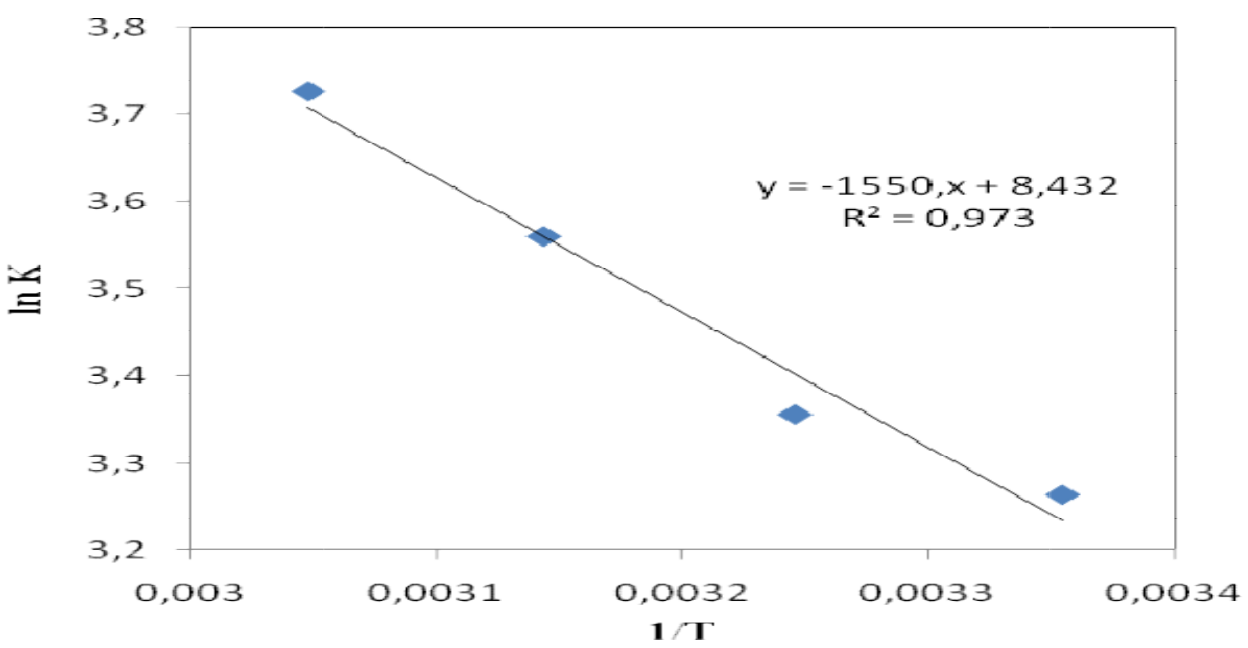

Fig.-28: Plot of $\ln \mathrm{K}$ Versus 1/T for the Enthalpy Change of the Adsorption Process for NMC. 
RASĀYAN J. Chem.

Vol. 13 | No. 1 |448 - 463| January - March | 2020

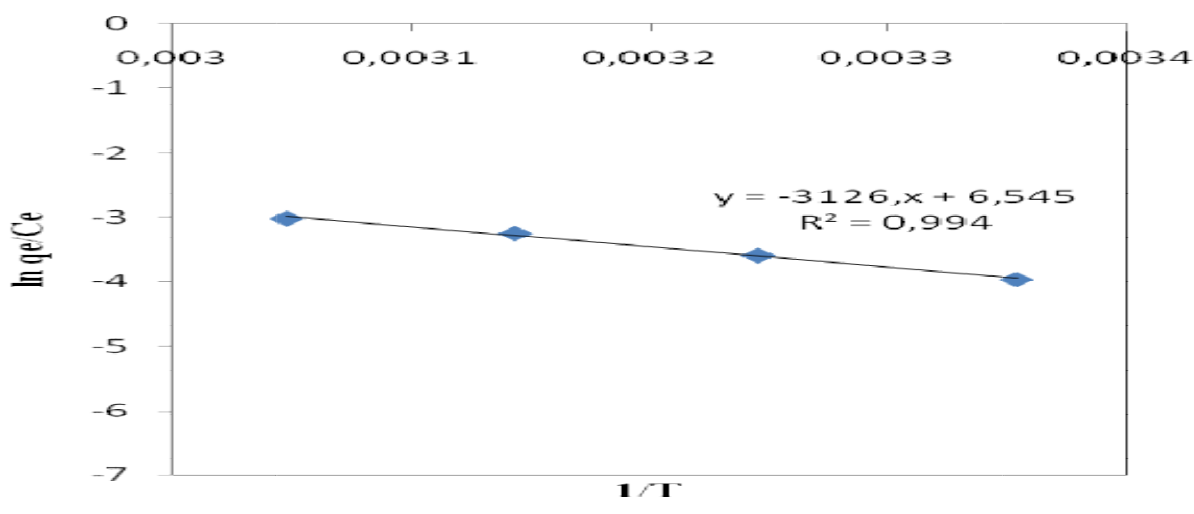

Fig.-29: Plot of ln K Versus 1/T for the Enthalpy Change of the Adsorption Process for EP.

\section{CONCLUSION}

This research assessed the possibility of using expanded Perlite and natural Moroccan clay as an efficient adsorbent for removing RB from aqueous solution. It was discovered that RB adsorption depends on the contact time, initial concentration, temperature and $\mathrm{pH}$ solution.

The results show that the amount of adsorbed RB increases with increasing temperature of the solution. In addition, the isotherms study reveal that the adsorption equilibrium follows the Langmuir model with maximum monolayer adsorption capacities of $68.493 \mathrm{mg} / \mathrm{g}$ for $\mathrm{NMC}$ and $7.510^{-3} \mathrm{mg} / \mathrm{g}$ for EP. The application of adsorption models of pseudo-first-order, pseudo-second-order and Intra-particle diffusion to the experimental results shows that the pseudo-second-order model describes better the process of adsorption of RB.

Regarding the thermodynamic study showed that the adsorption process is endothermic and its reaction is spontaneous.

Finally, the use of natural Moroccan clays shows a greater potential to remove textile dyes as accessible, low-cost adsorbent and no expensive equipment is required.

\section{REFERENCES}

1. M. El Alouani, S. Alehyen, M. El Achouri, M. Taibi, Journal of Chemistry, 1(14) (2019). DOI:10.1155/2019/4212901

2. M. El Alouani, S. Alehyen, M. El Achouri, M. Taibi, Chemical Data Collections, 23, (2019), 100265. DOI: $10.1016 /$ j.cdc.2019.100265

3. B. Damiyine, A. Guenbour, R. Boussen. Journal of Materials and Environmental Science, 8(3), 960(2017)

4. S. Banerjee, S. Dubey, R. K. Gautam, M. C. Chattopadhyaya, et Y. C. Sharma, Arabian Journal of Chemistry,10, s1629(2017), DOI: 10.1016/j.arabjc.2016.12.016

5. A. Tahiri, P. Montero, H. El Hadi, D. Martínez Poyatos, A. Azor, B. Bea, and others. Journal of African Earth Sciences, 57, 1(2010), DOI: 10.1016/j.jafrearsci.2009.07.005

6. B. Damiyine, A. Guenbour, R. Boussen, R. Journal of Materials and Environmental Science, 8(1), 345(2017)

7. E.S. Vasquez, J. L. Cunningham, J. B. McMahan, C. L. Simpson and K.B. Walters, Journal of Materials Chemistry, 3, 6411(2015), DOI: 10.1039/C5TB00565E

8. M. Doğan, M. Alkan and Y. Onganer, Water, Air, and Soil Pollution, 120, 229(2000)

9. F. Mahammedi, B. Benguella. Journal of Materials and Environmental Science, 7, 285(2016)

10. P. Pranoto, C.Purnawan, T.Utami, Rasayan Journal of Chemistry,11, 23(2018), DOI: 10.7324/RJC.2018.1111939

11. I. Langmuir, Journal of the American Chemistry Society, 38(11), 2221(1916), DOI: ORG/10.1021/JA02268A002 
RASĀYAN J. Chem.

Vol. 13 | No. 1 |448 - 463| January - March | 2020

12. M.M. Abd El-Latif and M.F. Elkady, Desalination, 255, 21(2010), DOI:10.1016/ j.desal.2010.01.020

13. H.M.F. Freundlich, The Journal of Physical Chemistry,57A, 385(1906), DOI: 10.1021/j150622a009

14. C. Aharoni and M. Ungarish, Journal of Chemical Society. Faraday Transactions 1: Physical Chemistry in Condensed Phases, 73, 456(1977)

15. A. Dumanski, Colloid \& Polymer Science, (2), 15(1907)

16. Y.S. Ho and G. McKay, Chemical Engineering Journal, 70, 115(1998), DOI:10.1016/S09230467(98)00076-1

17. C.J. Morris and W.J. Weber, Advances in Water Pollution Research, Pergamon, pp. 231-66 (1964)

18. Y. Rakhila, A. Mestari, S. Azmi and A. Elmchaouri, Rasayan Journal of Chemistry, 11(4), 1552(2018), DOI:10.31788/RJC.2018.1144025

19. R. Ali, H. Hamad, M.M. Hussein and G.F. Malash, Ecological Engineering, 91, 317(2016), DOI: 10.1016 / j.ecoleng.2016.03.015

20. Z. Al-Qodah, M. Al-Shannag, A. Amro, E. Assirey, M. Bob, K. Bani-Melhem and M. Alkasrawi, Turkish Journal of Chemistry, 41, 190(2017)

21. R. Elmoubarki, F.Z. Mahjoubi, H. Tounsadi, J. Moustadraf, M. Abdennouri, T. Zouhri, Abderrazak El Albani and N. Barka, Water Resources and Industry, 9, 16(2015)

22. N. Ganapathy Ramasamy, R. Dhanya, Rasayan Journal of Chemistry, 10(2), 577(2017), DOI: $10.7324 /$ RJC.2017.1021671

[RJC-5588/2019] 